\title{
Energy, economic and environmental analysis of fuzzy logic controllers used in smart buildings
}

\author{
Ali M Baniyounes ${ }^{1}$, Yazeed Yasin Ghadi ${ }^{2}$, Maryam Mahmoud Akho Zahia ${ }^{3}$, Eyad Adwan ${ }^{4}$, \\ Kalid Oliemat ${ }^{5}$ \\ ${ }^{1,3,4}$ Department of Electrical Engineering, Applied Science Private University, Jordan \\ ${ }^{2}$ Software Engineering and Computer Science, Al Ein University, UAE \\ ${ }^{5}$ Department of Electrical Engineering and Computer Science, Ohio North University, USA
}

\begin{abstract}
Article Info
Article history:

Received Sep 28, 2020

Revised Mar 21, 2021

Accepted May 5, 2021

\section{Keywords:}

Energy savings

EnergyPlus

Fuzzy logic

Life cycle

Smart buildings

ABSTRACT

This article is divided into three parts: the first presents a simulation study of the effect of occupancy level on energy usage pattern of engineering building of applied science private university, Amman, Jordan. The simulation was created on simulation mechanism by means of EnergyPlus software and improved by using the building's data such as building's as built plan, occupant's density level based on data about who utilize the building throughout operational hours, energy usage level, heating ventilating and air conditioning (HVAC) system, lighting and its control systems. Data regarding occupancy density level estimation is used to provide the proposed controller with random number of users grounded on report were arranged by the university's facilities operational team. The other division of this paper shows the estimated saved energy by the means of suggested advanced addon, FUZZY-PID controlling system. The energy savings were divided into summer savings and winter savings. The third division presents economic and environmental analysis of the proposed advanced fuzzy logic controllers of smart buildings in Subtropical Jordan. The economic parameters that were used to evaluate the system economy performance are life-cycle analysis, present worth factor and system payback period. The system economic analysis was done using MATLAB software.
\end{abstract}

This is an open access article under the $\underline{C C B Y-S A}$ license.

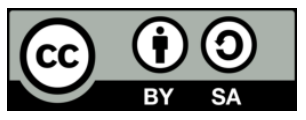

\section{Corresponding Author:}

Ali M Baniyounes

Department of Electrical Engineering

Applied Science Private University

Amman, Jordan

Email: al_younes@asu.edu.jo

\section{INTRODUCTION}

The main objective behind the smart buildings economic analysis is to determine the minimum cost of essential energy for delivering required thermal comfort conditions. In other words, the aim of the fuzzy control system is to establish a self-leaning control system that are able to deliver and assure the least cost arrangement of conventional control system and fuzzy control system in order to attain strong and convenient working place.

Buildings' users' number and occupancy density level influences usage of electrical lighting systems and heating ventilating and air conditioning (HVAC) system. The current part of this article presents the effect of occupants' concentration on energy consumption of HVAC and lighting systems in an intelligent building. The controller's input is provided by a random number generator based on the nature, details and 
operational pattern of the building. Results are carried out during building's normal working hours which is from 8 AM to $8 \mathrm{PM}$

The optimum option is to install a sub-main meter to evaluate the used energy by electrical-lighting systems at each level of the building. Practically, this means is not available and most of buildings utilizes a forecasted model to calculate energy used by lighting systems in the non-appearance of real data-loggers. The building's classified into different zones. It is to be noted that the designed lighting for these zones is different from lightings fixture power rating of primary design, in watts $/ \mathrm{m}^{2}$. Total energy used by the electrical lighting system is evaluated by using (1) [1].

$$
E_{\text {light }}=\sum_{n=1}^{N} \sum_{i=1}^{I} U_{i n} W_{i} A_{i} h_{n}
$$

here $\mathrm{N}$ is building's zones number, $\mathrm{U}$ : is electrical-lighting usage factor, $W_{i}$ is planned watt $/ \mathrm{m}^{2}$ of zones energy, $A$ is over-all floor area and $h$ is operational hours. In this article examples were acquired based on the period of usage which is estimated to be 3-5 hours.

The building's spaces are air-conditioned centrally by means of a chiller transporting water to airhandling units (AHU) that fitted in various zones. In general, the optimal of measuring energy usage by installing loggers that able to determine the HVAC energy demand. Accordingly, forecasted prototypes are important to calculate quantity the quantity of consumed energy grounded on heat-gain mathematical formulas [1]. The over-all cooling load $\left(Q_{t o t}\right)$ is the total of inner cooling-load and outdoor cooling-load [2][4]. Internal cooling-load is the outcome of tenants' capacity, electrical-lighting system and other gears computers. The key suppliers of out-of-doors cooling-load are ventilation, infiltration, conduction and radiation. The internal cooling-load is calculated from Equation 2 where the out-of-doors cooling-load is calculated from (2).

$$
Q_{i}=\left(\sum_{n=1}^{N} \sum_{i=1}^{I} U_{i n} W_{t} A_{i} h_{n}\right) * 1.2+\sum_{n=1}^{N} \sum_{d=1}^{D} U_{d n} P_{d} C_{d} h_{n}+\sum 0.15 * H_{a} h_{n}
$$

here $\mathrm{Ha}$ is tenants number, 1.2 is a multiplication factor for ballast losses [2], $D$ : equipment e.g. PC's, $U_{d n}$ : usage of gear of test d also period $n, P_{d}$ : consumed energy by equipment's and $C_{d}$ : tenants are utilizing electronics and $\mathrm{H}_{\mathrm{a}}$ is number of tenants.

$$
Q_{e}=\sum_{1}^{N} h_{n}\left(Q_{v}+Q_{i}+Q_{c}+Q_{r}\right)
$$

here $Q_{i}$; outdoor heat load $Q_{v}$ is energy used by ventilation, $Q_{i}$ : infiltration heat-load $Q_{c}$ : conductive heat load also $Q_{r}$; radiant heat-transfer.

The control technique began with evaluating sensible spans of occupancy level effect on the building's energy utilisation [3], [4]. The system's procedure of examination was executed by using EnergyPlus simulation engine. Randomly created patterns of occupants' action inputs were generated comprising a thorough record of equipment's computers in same time kept temperatures and humidity's users-set point.

The ordinary rates of resident profile were generated throughout a review of building energy efficiency code (Title 24) which is issued by Department of Energy for lists of occupants' activity and behaviour [3]. Moreover, the system-input has been classified to low-values (20-25\% of residents), medium (50-60\% of residents) in addition to elevated spans (90-100\% of residents). The previously mentioned lists of head counts are matched to any other official buildings' occupancy pattern. Process timetable were outlined to the model based to normal process changes in institutional building's normal business hours which are expressed in Table 1. It highlights the schedules which are exploited to mathematically-modelled occupant functions. Table 2, also outlines loads which are distressed by occupants-activity standards initiated by the existence of residents knowing that all electrical-receptacle, outlets as well as electrical-plugged loads are neglected. 
Table 1. Occupants and occupants' activity schedule

\begin{tabular}{|c|c|c|}
\hline EnergyPlus Factors & details & domains \\
\hline \multirow[t]{3}{*}{ Lightings' timetable } & Working hours & Low: less than, $4 \mathrm{hr} / \mathrm{d}, 10$ months/year \\
\hline & & Medium: ranging between 4 and $7 \mathrm{hr} / \mathrm{d}, 10$ months/year \\
\hline & & High: a day, $12 \mathrm{hr} / \mathrm{d} 10$ months/ year. \\
\hline \multirow[t]{3}{*}{ Equipment's' timetable } & Working hours & Low: less than, $4 \mathrm{hr} / \mathrm{d}, 10$ months/year \\
\hline & (plug-in load) & Medium: $4-7 \mathrm{hr} / \mathrm{d}, 10$ months/year \\
\hline & & High: a day, $12 \mathrm{hr} / \mathrm{d} 10$ months/year \\
\hline \multirow[t]{3}{*}{ Peoples' timetable } & Occupants' pattern & Low: less than, $50 \%$ of total occupants, 10 timetable \\
\hline & (ratio of people in to $\max$ & Medium: $50 \%$ of total occupants, 10 timetable \\
\hline & number of residents) & High: less than $100 \%$ to $50 \%$ of total residents 10 months/year \\
\hline
\end{tabular}

The methods which are stated in the previous table (Table 2) classifies the varieties of data that represents correct and sensible projections of standard occupants' behaviors and activity temperature variation also relative-humidity set points, windows' status, class rooms' occupation.

Table 2. Building's EnergyPlus profile

\begin{tabular}{|c|c|c|}
\hline EnergyPlus factors & Details & domains \\
\hline Programed temperature & $\begin{array}{l}\text { Programed Temperature } 20-23 \mathrm{C}^{\circ} \text { during } \\
\text { winter and } 24-26 \mathrm{C}^{\circ} \text { during summer }\end{array}$ & $\begin{array}{l}\text { Low: } 20-23 \mathrm{C}^{\circ} \\
\text { Medium: } 22-26 \mathrm{C}^{\circ} \\
\text { High: } 25-27 \mathrm{C}^{\circ}\end{array}$ \\
\hline $\begin{array}{l}\text { Programed Relative } \\
\text { Humidity }\end{array}$ & Programed Relative Humidity $40-70 \%$ & $\begin{array}{l}\text { Low: } 40-50 \% \\
\text { Medium: } 50-60 \% \\
\text { High: } 70-80 \%\end{array}$ \\
\hline Occupancy pattern & Occupant pattern in persons $/ \mathrm{m}^{2}$ & $\begin{array}{l}\text { Low: } 20 \text { people } / 100 \mathrm{~m}^{2} \\
\text { Medium: } 40 \text { people } / 100 \mathrm{~m}^{2} \\
\text { High: } 80 \text { people } / 100 \mathrm{~m}^{2}\end{array}$ \\
\hline Residents' heat load & $\begin{array}{l}\text { Sensible/Latent heat load-variation due to } \\
\text { individuals }\end{array}$ & $\begin{array}{l}\text { Low: } 35 \mathrm{kWh} / \text { person} / \mathrm{hr} \\
\text { Medium: } 75 \mathrm{kWh} / \text { person/hr } \\
\text { High: } 170 \mathrm{kWh} / \text { person } / \mathrm{hr}\end{array}$ \\
\hline Infiltration/ventilation & $\begin{array}{l}\text { Ventilation value and infiltration's } \\
\text { openings }\end{array}$ & $\begin{array}{l}\text { Low: } 0.20 \mathrm{CFM} / \text { head } \\
\text { Medium: } 0.40 \mathrm{CFM} / \text { head } \\
\text { High: } 0.75 \mathrm{CFM} / \text { head }\end{array}$ \\
\hline $\begin{array}{l}\text { Lighting/solar radiation } \\
\text { heat gain }\end{array}$ & $\begin{array}{l}\text { heat-gain-change due to lightings and sun } \\
\text { radiations measured class/hour }\end{array}$ & $\begin{array}{l}\text { Low: } 100 \mathrm{kWh} / \mathrm{class} / \mathrm{hr} \\
\text { Medium: } 150 \mathrm{kWh} / \mathrm{class} / \mathrm{hr} \\
\text { High: } 200 \mathrm{kWh} / \mathrm{class} / \mathrm{hr}\end{array}$ \\
\hline
\end{tabular}

The proposed fuzzy add On-PID controllers is resented to execute this computation. The proposed fuzzy add On-PID controllers' inputs are error $\mathrm{eR}$ and its variation $\Delta \mathrm{eR}$ that signifies the alteration amongst building's previous residents and building's present residents. Furthermore, the fuzzy add On-PID controllers' memberships functions' input and output are showed in Figure 1. The controller's inputs and outputs comprise this noted significances, high negative (HN), medium negative (MN), low negative (LN), zero (Z), low positive (LP), medium positive (MP) and high positive (HP) is presented in Table 3 [5]. the fuzzy add On-PID controllers' output is the important power variation depends on residency density level which necessitates to keep indoor thermal and visual comfort within standards.

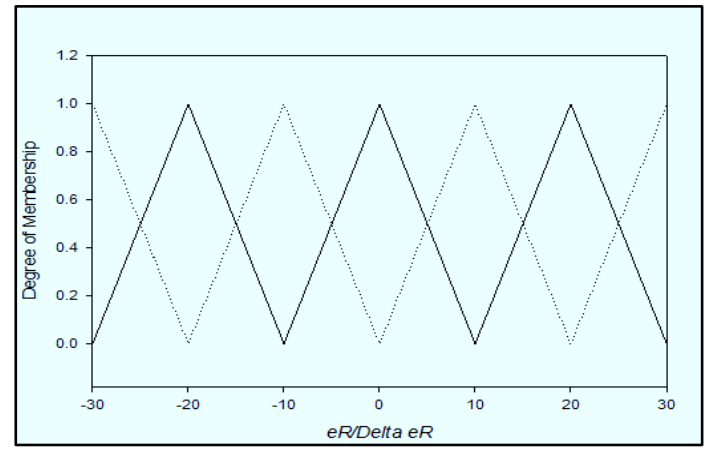

Table 3. Fuzzy control rules for local various occupancy levels

\begin{tabular}{lllllllll}
\hline \multicolumn{1}{c}{ Occupancy levels } \\
$\begin{array}{l}\text { Required } \\
\text { change in } \\
\text { energy }\end{array}$ & & HN & MN & LM & Z & LP & MP & LP \\
\hline$\Delta$ eR & HN & HN & HN & HP & HP & HP & HP & HP \\
& MN & HN & MN & Z & MP & MP & HP & HP \\
& LN & HN & MN & HN & HP & MP & HP & HP \\
& Z & HN & NM & HN & Z & PL & PM & HP \\
& PL & NH & NH & NM & NH & PL & PM & HP \\
& HN & HN & HN & HP & HP & HP & HP & HP \\
& MN & HN & MN & Z & MP & MP & HP & HP \\
\hline
\end{tabular}

Figure 1. Membership functions of various occupancy levels 


\section{RESULTS AND DISCUSSION}

The current part of the article, presents the study's outcome mean while it provides a detailed discussion and results analysis. All study outcomes and results are shown in figures and tables to allow readers to comprehend the study easily. The results' discussions are detailed below in several sub sections.

\subsection{Energy savings and energy index}

Figure 2 displays building's gross electrical load in the year 2016 which was 643575kWh. Throughout the hot-seasons and thus, excessive request for air conditioning which normal occurs in May to mid-November. Also demands on heating is occurred in December to March. The building's peak energy demand was recorded through the month of January at $68350 \mathrm{kWh}$ followed by the months of February at $65140 \mathrm{kWh}$, then the month of April at $61925 \mathrm{kWh}$. During cold seasons when heating and cooling energy demand was low, the minimum energy load was in the month of August at $42690 \mathrm{kWh}$ tailed by the month of June at $45015 \mathrm{kWh}$ also in August at $48010 \mathrm{kWh}$ correspondingly.

Furthermore, Figure 2 displays building's gross electricity demand when the occupancy level is $100 \%, 50 \%$ and $25 \%$. At $50 \%$ occupancy level, the gross electrical load throughout the year decreased from $643.575 \mathrm{kWh}$ to $550.320 \mathrm{kWh}$ which shows electrical-energy savings of about $15 \%$. As already noted from Figure 2 the most energy saving of $20.480 \mathrm{kWh}$ was in the month of April which is equal to about $40 \%$, tailed by March, November at proportion of $25 \%, 21 \%, 20 \%$ correspondingly. The cause of April has the most saved energy is because of holiday seasons. Eid, Christmas and the New Year. The lowest saved energy is occurred in the September where the start of the academic calendar.

A like situation was achieved at $24 \%$ residency rate. For $24 \%$ occupancy level, the total annual load was found to be $468.435 \mathrm{kWh}$ which accounts for about $26 \%$ electric demand saving compared to $100 \%$ residency rate. During December outcomes were yet the most saved energy which is around 30\% due for holiday's seasons and the lowers energy savings were occurred in the month of March which was about $20 \%$ energy savings compared to the full residency rate.

The overall quantity of used energy concentration is measured as an indicator of the yearly electricity utilization of $\mathrm{HVAC}$ as well as lighting system in $\mathrm{kWh} / \mathrm{m}^{2}$ such as standardised electricity utilization. The constraint of energy usage intensity is that it does not consider elements that include energy utilization for HVAC and lightings' systems efficiency individually [6]. Energy endorsement is used as an auxiliary to regulate energy usage intensity to measure the energy performance of HVAC and lightings' system with various operational conditions and operational modes [7]. Energy endorsement models are depleted for a long time in order to calculate and control buildings' energy performance in different climatic conditions.

Energy's practice prifile is the tendency of yearly consumed energy of institutional buildings compared to average outdoor temperature at a certain time intermission (one hour, one day or one month). It not only unveiled the building total energy usage but also demonstrates the effect of climatic conditions on energy usage pattern of HVAC [8]. Seeing energy management of buildings and climatic information, it is probable to compute variances in HVAC 's and lighting systems' way of control. As climatic circumstances influence the way of buildings' HVACs and lightings load variations, it is essential to utlize used energy pattern prototypical HVACs' and lightings systems' energy efficiency under changing buildings cooling and lightings load [9]. This article, energy practice model was commissioned to itemize annual HVACs' and lighting systems' energy utilization knowing that, diverse energy efficiency measures. The simulation's results specifies that energy procedure pattern could be engaged to organize HVACs' and lighting systems' energy efficiency and implement add-on-fuzzy control systems. Energy preservation strategies is the most suitable way of lessening HVACs' and lighting systems' energy use throughout peak-time demands of HVACs' load. To economically control annual HVACs and lighting systems' energy usage, various references energy usage prifile have been produced in this research to support the usage of different passive cooling methods the usage of shadowers to shield from sun radiant heat increase. The simulation manner explains on way of total HVACs' and lighting systems' energy usage differ in respect to climatic data profile knowing that diverse means for base climatic gain. 


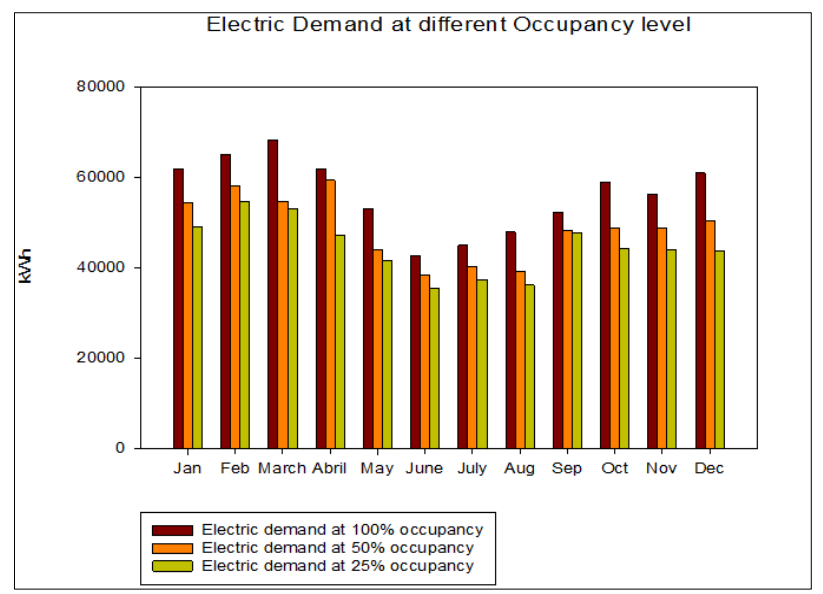

Figure 2. Building's total electric load at different occupancy level

Energy mark used in HVACs and lighting systems is likened to fuzzy logic controller the handling of external air temperature and humidity whem lies between 18-27C and 35-70\% respectively as presented in Figure 3. currently, the usage of outdoor air outcomes the utmost energy performance (the least energy utilization, $\mathrm{kWh} / \mathrm{m}^{2}$ ) related to the reachable controling system. The computed data utilization of used-energy were connected to its semilar climatical index. The factors of determination (R2) diverse from 0.90 to 0.96 showing a significant association of the energy usage with the climatal index such as temperature, relative humidity and illuminanation).

Consequently, the energy's usage profile models with various retrofit tactics could be utlized to classify the controlling way trhouout building's resident profile which might have changed [10]-[15].To calculate the saved energy using the sugested fuzzy-logic controller, the building's HVACs and lightings' systems electrical power usage is operated using regular Proportional integral derivative PID controller which was evaluated compared to the proposed fuzzy logic controller, as presented in Figure 4.

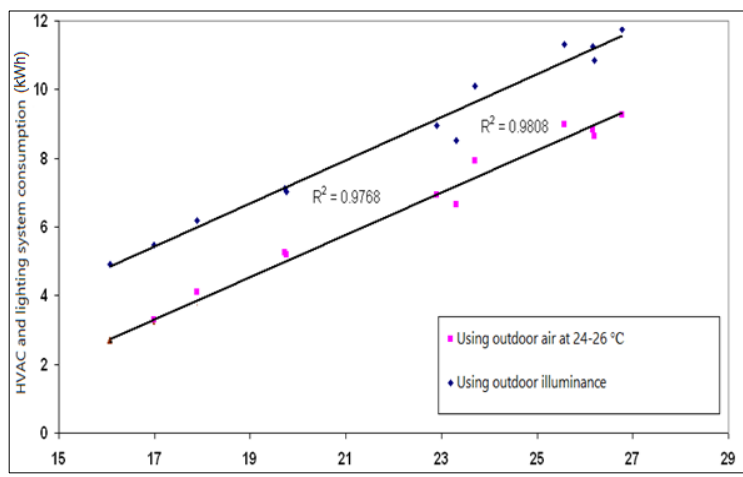

Figure 3. Energy index using outdoor air and daylight

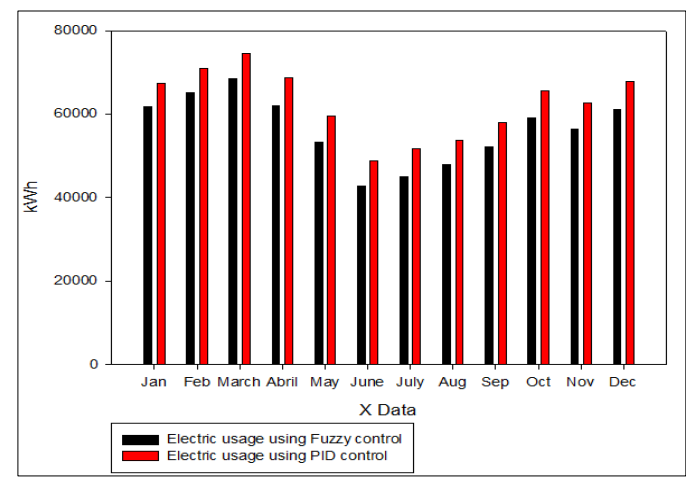

Figure 4. Energy savings PID vs fuzzy logic

\subsection{Life cycle cost (LCC) analysis control}

Fuzzy-logic-based controllers for smart buildings are characterized by a high capital investment including the cost of design, programming and installation. The costs of fuzzy-logic-based control system involves the costs required for utilizing ambient air, daylighting, the consideration of occupancy density level and the normal operation of the existing HVAC and lighting system. Installation costs of fuzzy-logic controllers' equipment $C_{f}$ can be expressed as the sum of three items given in (1) [15]-[17].

$$
C_{f}=C_{c}+C_{s}+C_{s e}
$$


Where $\mathrm{C}_{\mathrm{c}}$ is the capital costs, $C_{\text {ase }}$ is the sensor cost and $C_{s}$ is the software costs of the fuzzy logic controllers, all in Jordan Dinars.

In this study, LCC analysis was used as the indicator of economic performance. The evaluation was performed by comparing the values of LCC obtained for various control strategies. Both capital and operational costs were considered for various retrofit control techniques.

Varun Chaudhary, et al. [8] performed LCC analysis using present worth factor technique by employing a comprehensive load portfolio, and the initial and operational cost of HVAC systems. During evaluation, they considered two dissimilar function or type of building, two dissimilar operational setups for HVAC system and two dissimilar economic considerations. [9] explained theoretical problems tied with LCC analysis for an Jordan constructed case study building in assessing substitute design technologies to achieve energy efficient buildings.

Harish Kumar, et al. [9], Yiwen Ji, et al. [10] carried out a LCC analysis of 60 residential and commercial buildings from different nations and reported that operational energy is the biggest portion of buildings energy consumption throughout its life cycle [11]. The project showed a linear interpolation between working and gross energy usable over all situation's despite of climatic conditions and other situation variation and revealed that design of energy efficient buildings produces net profit in gross LCC energy consumption. [13] investigated the significance of LCC energy analysis and concluded that operational energy is a key element of the LCC energy usage.

Life cycle cost analysis accounts present and future costs of energy conservation strategies over its life-cycle. In this study, the LCC analysis of various energy retrofit in building was done using (2)[11].

$$
L C C=I+C c+E+O M \& R-R E S
$$

where LCC is life cycle cost analysis, Cc is capital cost, E is energy cost and OM\&R is operating and maintenance cost.

Several data are required for assessing a substitute control system. The data involves the costs of energy, system installation, operating and maintenance, etc. Some of the data were hard to obtain. Energy resources cost is very significant throughout a building's lifecycle because it is the biggest share of commercial building cost during the buildings' lifespan. The cost of energy usage was determined in this study by creating numerous computations using simulation engines and thus attained the yearly buildings' energy usage based on building's specifications and its envelope's features, heat gains, and type of existing HVAC system [17]-[19].

Regarding every fuzzy logic control technique, a base model was created by MATLAB and EnergyPlus simulation engines. The execution of the base model represents the conduct of the current building within the influence of the different control situations. Later on, this base model was equated to different models with respect to different refurbishment decisions.

\subsection{Data for cost estimation}

The expected life time of the proposed system was considered 20 years. The non-repeated operational and maintenance costs were considered to kick off after 10 years of the initial installation. In the analysis, the current (2017) Dinar value was considered constant throughout the year. Operational and maintenance costs were assumed to be same. Annual re-occurring cost such as energy costs, operation and maintenance costs were assumed to occur after the beneficiary date from January 1, 2016 and are discounted to present value until the end of the study period.

Table 4 shows the data for cost estimation using fuzzy-logic-control system. Throughout system evaluation net savings in energy substitutes do not oblige a spare part changing since the appropriate lifetime is expected to be the same as 20 years.

Table 4. Data Summary for cost estimation

\begin{tabular}{lll}
\hline Cost Items & Conventional control strategies & Fuzzy logic control strategies \\
\hline Annual electricity consumption & $643.572 \mathrm{kWh}$ & $643.572 \mathrm{kWh}$ \\
Electricity price per kWh & $\$ 0.06270$ & $\$ 0.06270$ \\
Initial investment cost & $\$ 156.000$ & $\$ 156,000$ \\
Expected asset life & 20 years & 20 years \\
Outstanding asset factor & $8 \%$ & $8 \%$ \\
Main maintenance and substitute cost & JD12.500 & JD 12.500 \\
Yearly regular continuous operational and maintenance costs & JD 1.200 & JD 1.200 \\
Regular one-time operational and maintenance costs & JD 11.000 & JD 11.000 \\
\hline
\end{tabular}


The capital costs were regarded to be around JD 85,000, similar to the cost of similar control system in Applied Science Private University, Amman, Jordan. As per literature, the initial costs for installing a fuzzy logic control system were considered to be JD12500. The cost of the rest of gear is expected to be the same for all other systems. The useful life span of the installation is projected to be 20 years for existing systems. The cost of energy was priced per $\mathrm{kWh}$ and is gathered from local energy provider Jordan. Yearly repeated operational and maintenance costs are regarded to be around JD1200 as counted by Applied Science Private University department of facilities management.

\subsection{Data for cost estimation}

The Table 5 shows the computed life cycle costs summary for all base case conventional control system and fuzzy-base-control system. The fuzzy base control system delivers the least LCC over the 20 years' project duration. Base Case conventional control system is also cost effective economic measure in spans of LCC and yearly cost matched to the reference case. Between conventional control system and fuzzybase-control system, fuzzy-base-control system has the smallest LCC of JD 680.500 which indicates net savings of JD175.000 (JD 855.500-680.500) which equates to 20.4\% LCC savings.

Table 5. Life cycle cost summary

\begin{tabular}{|c|c|c|c|c|}
\hline \multirow[t]{2}{*}{ Cost items } & \multicolumn{2}{|c|}{$\begin{array}{c}\text { Base Case conventional control } \\
\text { system }\end{array}$} & \multicolumn{2}{|c|}{ Fuzzy base control system } \\
\hline & Present value & Annual value & Present value & Annual value \\
\hline Initial cost & JD 156.000 & JD 7008 & JD 220.000 & JD 11.000 \\
\hline Energy consumption costs & JD 671.161 & JD 56.227 & JD 496.101 & JD 41.561 \\
\hline Regular yearly repetitive operation and maintenance costs & JD 13.500 & JD 1.150 & JD 13.500 & JD 1.150 \\
\hline Regular one-time operation and maintenance costs & JD 10.500 & JD 850 & JD 10.500 & JD 850 \\
\hline Main maintenance and spare parts replacement costs & JD 12.500 & JD 1.010 & JD 12.500 & JD 1.010 \\
\hline Least residual value & JD 7.080 & JD 600 & JD 7.080 & JD 600 \\
\hline Total Life-Cycle Cost & JD 855.500 & JD 71.900 & JD 680.500 & JD 57.000 \\
\hline
\end{tabular}

Table 6 demonstrate energy savings of proposed fuzzy logic control system. The reference buildings control technique energy consumption was $643.572 \mathrm{kWh}$. For Fuzzy base control system, the average expected energy consumption is $585.000 \mathrm{kWh}$. Energy savings are $62.248 \mathrm{kWh}$ annually which equates to about $10 \%$ savings. The LCC energy savings is about $124.496 \mathrm{kWh}$.

Table 6. Energy savings summary

\begin{tabular}{ccccc}
\hline \multirow{2}{*}{ Type } & Base Case conventional control system in kWh & \multicolumn{2}{c}{ Fuzzy base control system usage in kWh } \\
& Average & Annual & Savings & Life cycle savings \\
\hline Consumption & 643.572 & 585.000 & 62.248 & 124.496 \\
\hline
\end{tabular}

\subsection{Payback period estimation}

The payback period $N_{P}$ given in (6) is generally used within buildings economic purposes to forecast the time to cover its capital cost [12].

$$
N_{P}=\frac{\ln \left[\frac{\mathrm{C}_{\mathrm{S}} \times i}{S F \times L \times C_{F}}+1\right]}{\ln (1+i)}
$$

Where $C_{F}$ is the first period's unit energy cost delivered from regular fuel (JD), $L$ is the yearly load (kWh) and $S F$ is the annual fuzzy fraction [20].

Figure 5 shows the accumulative of the proposed control system's costs savings in respect to time. The overall time needed to produce zero cash is nearly nine years, whereas the time required for total energy savings to match the capital investment of JD 156.000 (payback time) is about 15 years. 


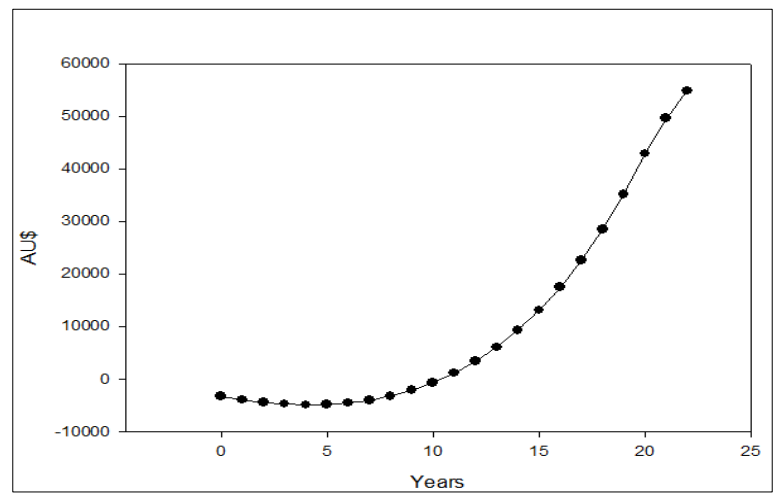

Figure 5. Proposed system payback period

\subsection{Payback period estimation}

Smart buildings application delivers a possibility of minimizing the electrical energy in a way that it will direct to substantial reduction in $\mathrm{CO}_{2}$ emissions. The environmental evaluation of the proposed control system depends on the avoided amount of $\mathrm{CO}_{2}$ emissions caused by electricity savings which can be expressed using (7).[21]-[23].

$$
\mathrm{CO}_{2} \text { (Avoided) }=\mathrm{CO}_{2} \text { Factor } \times E_{S}
$$

here $\mathrm{CO}_{2}$ factor is defined as the emission factor and $E_{S}$ is total energy savings. The highest source of electricity generation in Jordan is heavy fuel which produces about $85 \%$ of the country's total electricity production. Consequently, decrease in using coal in electric power generation plants will enhance the environmental conditions of Jordan.

As reported by the Jordanian office of climate, the CO2 factor is about $88.2 \mathrm{~g} / \mathrm{kWh}$. The overall annual emission is recognized to be one of the most significant indicators of the environmental measures and assessment [24], [25]. Figure 6 shows that using proposed control system, the yearly eliminated greenhouse gas emission is nearly 25.5 tons of $\mathrm{CO} 2$ by applying the most of fuzzy role sets.

As reported by the Jordanian office of climate, the CO2 factor is about $88.2 \mathrm{~g} / \mathrm{kWh}$. The overall annual emission is recognized to be one of the most significant indicators of the environmental measures and assessment [26]. Figure 6 shows that using proposed control system, the yearly eliminated greenhouse gas emission is nearly 25.5 tons of $\mathrm{CO} 2$ by applying the most of fuzzy role sets.

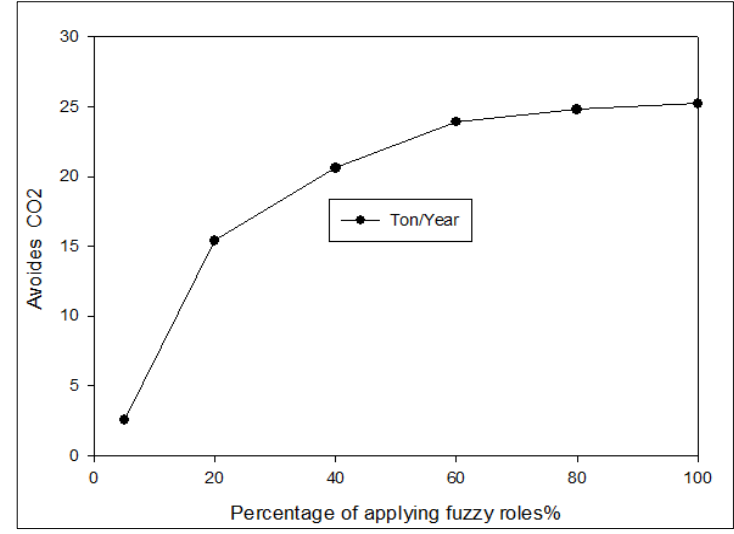

Figure 6. Annual avoided $\mathrm{CO} 2$ emissions

\section{CONCLUSION}

This article presents the effect of occupancy concentration level on an energy savings of Applied Science Private University, Amman, Jordan. The occupancy density of $100 \%, 50 \%$ and $25 \%$ was considered to investigate their impacts on HVAC and Lighting system energy demand. The results showed that 
building's control system can save about $14 \%$ of total energy demand at $50 \%$ of occupancy level and $24 \%$ at $25 \%$ occupancy level compared to full (100\%) occupancy level. Moreover, for $100 \%$ occupancy level, the energy savings of $9 \%-14 \%$ can be achieved, with maximum energy savings in July (15\%) and minimum energy savings in January (9\%) if the proposed fuzzy logic controller can be introduced. The results proved that smart buildings and building intelligent control systems are able to save energy by applying a set of rules which are based on real life events such as the usage of daylight, weather data, sun radiation, occupant's density and etc.

Economic performance of building management control technologies is also assessed for the reference building. The research has revealed that although the fuzzy-control system requires more capital cost in comparison to conventional control techniques, the $10 \%$ savings in operation energy are adequate to justify the extra capital investment).

\section{REFERENCES}

[1] Younis, Ossama, Marwan Krunz, and Srinivasan Ramasubramanian, "Node clustering in wireless sensor networks: Recent developments and deployment challenges," IEEE network, vol. 20, no. 3, pp. 20-25, 2006, DOI: 10.1109/MNET.2006.1637928.

[2] Chirarattananon, Surapong, and Juntakan Taweekun, "A technical review of energy conservation programs for commercial and government buildings in Thailand," Energy Conversion and Management, vol. 44, no. 5, pp. 743762, 2003, DOI: 10.1016/S0196-8904(02)00082-1.

[3] M A de Wit, M P Koopmans, L M Kortbeek, W J Wannet, J Vinjé, F van Leusden, et al., "Sensor, a populationbased cohort study on gastroenteritis in the Netherlands: incidence and etiology," American journal of epidemiology, vol. 154, no. 7, pp. 666-674, 2001, DOI: 10.1093/aje/154.7.666.

[4] DomenicoMazzeo, Nicoletta Matera, Cristina Cornaro, Giuseppe Oliveti, Piercarlo Romagnoni, and Livio De Santolid, "EnergyPlus, IDA ICE and TRNSYS predictive simulation accuracy for building thermal behaviour evaluation by using an experimental campaign in solar test boxes with and without a PCM module," Energy and Buildings, vol. 212, 2020, DOI: 10.1016/j.enbuild.2020.109812.

[5] Ali M. Baniyounes, Yazeed Yasin, Ghadi, M.G. Rasul and M.M.K. Khan, "An overview of solar assisted air conditioning in Queensland's subtropical regions," Australia. Renewable and Sustainable Energy Reviews, vol. 26, pp. 781-804, 2013, DOI: 10.1016/j.rser.2013.05.053.

[6] Ali M. Baniyounes, Gang Liu, M.G. Rasul and M.M.K. Khan, "Comparison study of solar cooling technologies for an institutional building in subtropical Queensland, Australia," Renewable and Sustainable Energy Reviews, vol. 23, pp. 421-430, 2013, DOI: 10.1016/j.rser.2013.02.044.

[7] Suping Zhao, Daiying Yin, Ye Yu, Shichang Kang, Dahe Qin, and Longxiang Dong, "PM2. 5 and O3 pollution during 2015-2019 over 367 Chinese cities: spatiotemporal variations, meteorological and topographical impacts," Environmental Pollution, vol. 264, 2020, DOI: 10.1016/j.envpol.2020.114694.

[8] Varun Chaudhary, Vishal Soni, Bharat Gwalani, R.V. Ramanujan, and Rajarshi Banerjee, "Influence of nonmagnetic $\mathrm{Cu}$ on enhancing the low temperature magnetic properties and Curie temperature of $\mathrm{FeCoNiCrCu}(\mathrm{x})$ high entropy alloys," Scripta Materialia, vol. 182, vol. 6, pp. 99-103, 2020, DOI: 10.1016/j.scriptamat.2020.02.037.

[9] Harish Kumar, Piyush Kumar Sahu, and Subhash Chand, "Thermal performance and heat transfer analysis of arc shaped roughened solar air heater-An experimental study," Solar Energy, vol. 199, pp. 173-182, 2020, DOI: 10.1016/j.solener.2020.01.068.

[10] Yiwen Ji, Lingxia Xu, Xiaotao Hao, and Kun Gao, "Energy loss in organic solar cells: mechanisms, strategies, and prospects," Solar RRL, vol. 4, no. 7, 2020, DOI: 10.1002/solr.202000130.

[11] Gerald A. Meehl, Thomas F. Stocker, William Collins, Pierre Friedlingstein, Amadou Gaye, Jonathan Gregory, et al., "Global climate projections," Climate Change, 2007, pp. 747-845.

[12] DiLouie, C., Advanced lighting controls: energy savings, productivity, technology and applications, The Fairmont Press, Inc, 2006.

[13] Norton, D.I., "Elementary school utilizes solar design techniques and groundwater cooling system for energy efficiency," ASHRAE Journal, vol. 37, no. 3, pp. 50-52, Mar 1995.

[14] Baniyounes, Ali M., "Renewable energy potential in Jordan," International Journal of Applied Engineering Research, vol. 12, no. 19, pp. 8323-8331, 2017.

[15] ewis G. Harriman, Michael J. Witte, Marek Czachorski and Douglas R. Kosar, "Evaluating active desiccant systems for ventilating commercial buildings," ASHRAE Journal, vol. 41, no. 10, pp. 28-37, 1999.

[16] Christopher, S., "Ventilation in the commercial environment," ASHRAE Journal, vol. 41, no. 10, pp. 73-6, 1994.

[17] Wang, Y. and P. Dasgupta, "Designing an adaptive lighting control system for smart buildings and homes," 2015 IEEE 12th International Conference on Networking, Sensing and Control, 2015, DOI: 10.1109/ICNSC.2015.7116079.

[18] Beckel, C., et al. "Automated customer segmentation based on smart meter data with temperature and daylight sensitivity," 2015 IEEE International Conference on Smart Grid Communications (SmartGridComm), Miami, FL, USA, 2015, IEEE, DOI: 10.1109/SmartGridComm.2015.7436375.

[19] Luigi Martirano, Giuseppe Parise, Luigi Parise, and Matteo Manganelli, "Simulation and sensitivity analysis of a fuzzy-based building automation control system," 2014 IEEE Industry Application Society Annual Meeting, 2014, 
DOI: 10.1109/IAS.2014.6978480.

[20] da Fonseca, R.W., E.L. Didoné, and F.O.R. Pereira, "Using artificial neural networks to predict the impact of daylighting on building final electric energy requirements," Energy and Buildings, vol. 61, pp. 31-38, 2013, DOI: 10.1016/j.enbuild.2013.02.009.

[21] Mousa Marzband, Andreas Sumper, Mircea Chindris, and Bogdan Tomoiaga, "Energy management system of hybrid microgrid with energy storage," 9th World Energy Systems Conference: Towards Sustainable and Integrated Energy Systems, WESC 2012, June 28-30 2012, Suceava, Romania, 2012.

[22] Maamari, F and M. Fontoynont. "Use of IEA-SHC Task $21 \mathrm{C}$ benchmarks to assess performance of Lightscape 3.2 in daylighting calculations," Proceedings of EPIC Conference, Lyon, France, 2002.

[23] Cziker, A., M. Chindris, and A. Miron, "Fuzzy controller for indoor lighting system with daylighting contribution," ELECO'2007 5th International Conference on Electrical and Electronics Engineering, 2007.

[24] Cziker, A., M. Chindris, and A. Miron, "Fuzzy controller for a shaded daylighting system," 2008 11th International Conference on Optimization of Electrical and Electronic Equipment, 2008, DOI: 10.1109/OPTIM.2008.4602522.

[25] Abdallah, Salah, "Productivity enhancement of solar still with PV powered heating coil and chamber step-wise basin," Journal of Ecological Engineering, vol. 19, no. 2, 2018, DOI: 10.12911/22998993/81238.

[26] Abu Baker, A., and Ghadi, Y., "A novel CAD system to automatically detect cancerous lung nodules using wavelet transform and SVM," International Journal of Electrical and Computer Engineering (IJECE), vol. 10, no. 5, pp. 4745-4751, 2020, DOI: 10.11591/ijece.v10i5.pp4745-4751. 